\title{
Total coronary revascularisation in a young patient with acute coronary syndrome and multivessel disease
}

\author{
Zoran Miovski*, \\ Kristina Marić Bešić, \\ Maja Strozzi, \\ Joško Bulum \\ University of Zagreb \\ School of Medicine, \\ University Hospital \\ Centre Zagreb, Zagreb, \\ Croatia
}

KEYWORDS: coronary artery disease, multivessel disease, young patient. CITATION: Cardiol Croat. 2016;11(3-4):104. | DOI: http://dx.doi.org/10.15836/ccar2016.104 *ADDRESS FOR CORRESPONDENCE: Zoran Miovski, Klinički bolnički centar Zagreb, Kišpatićeva 12, HR-10000 Zagreb, Croatia. / Phone: +385-98-464-811 / E-mail: miovski.zoran@gmail.com ORCID: Zoran Miovski, http://orcid.org/0000-0002-3850-8905 • Kristina Marić Bešić, http://orcid.org/0000-0002-4004-7271 Maja Strozzi, http://orcid.org/0000-0003-4596-8261 • Joško Bulum, http://orcid.org/0000-0002-1482-6503

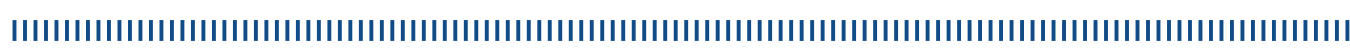

Introduction: Among patient with unstable angina and myocardial infarction without ST segment elevation, about $40-60 \%$ have multivessel coronary disease. Due the lack of specific recommendations we decided to present a case of young patient with acute coronary syndrome and multivessel disease. Case report: 36-year-old male patient was admitted to our hospital from emergency department (ER) because of chest pain in the last 2 months during a low level of activity. He had moderate dyslipidaemia that was not treated. On the day he was hospitalized a treadmill test was done, with clinically positive test, and $3 \mathrm{~mm}$ ST-segment depression in inferolateral leads at 6 metabolic equivalents (MET). In the ER, the standard 12-lead electrocardiogram and laboratory tests (troponin T) were normal. Echocardiography showed left ventricular ejection fraction of 55\% with hypocontractility of interventricular septum, inferior and distal part of anterolateral wall. The same day coronary angiography was done according to European Society of Cardiology Guidelines ${ }^{1}$ and revealed multivessel disease, bifurcational high significant stenosis left anterior descending artery/first diagonal (MEDINA $1,1,1)$, suboclusive stenosis of strong first obtuse marginal and occlusion of right coronary artery with autocollaterals and collaterals form left coronary arteries. The patient was referred to the heart team, and complex three vessel percutaneus coronary intervention (PCI) was indicated. Coronary intervention resulted in total coronary revascularization and optimal result. Seven days after admission the patient was discharged from our hospital.

Conclusion: The present studies suggest that multivessel coronary intervention despite a lack of impact on mortality is associated with a lower repeat revascularization rate, compared to culprit lesion PCI. According to the guidelines decision should be made based on the patient state, lesion characteristics and degree of myocardial damage. Due the lack of studies, the choice between multivessel PCI and culprit PCI rests mostly on operator.
RECEIVED:

February 9, 2016

ACCEPTED:

February 20, 2016

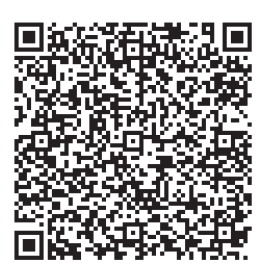

1. Roffi M, Patrono C, Collet JP, Mueller C, Valgimigli M, Andreotti F, et al. 2015 ESC Guidelines for the management of acute coronary syndromes in patients presenting without persistent ST-segment elevation: Task Force for the Management of Acute Coronary Syndromes in Patients Presenting without Persistent ST-Segment Elevation of the European Society of Cardiology (ESC). Eur Heart J. 2016;37(3):267-315. DOI: http://dx.doi.org/10.1093/eurheartj/ehv320 